\title{
Correction to: The Electric Car
}

\author{
Oliver Schwedes and Marcus Keichel
}

\section{Correction to: \\ O. Schwedes, M. Keichel (eds.), The Electric Car, https://doi.org/10.1007/978-3-658-29760-2}

The original version of the book was inadvertently published without the following corrections. The chapters have now been corrected.

\section{Corrections:}

Page iv: "A subsequent human revision was done primarily in terms of content." has been changed to "The translation was then subjected to a substantial revision for accuracy and style by Gregory Sims."

Page 2, line 9: "Actors from Politics, Research and Industry (Picture 1.1)" has been changed to "Actors from Politics, Research and Industry"

Page 16, line 5: "Dependence on Political and Economic History (Fig. 2.2)" has been changed to "Dependence on Political and Economic History"

The updated online version of this book can be found at https://doi.org/10.1007/978-3-658-29760-2 
Page 18, line 13: "For the former group, the car was partly a machine for sport and pleasure, partly an object that met the requirements of representing status." has been changed to "For the former group, the car was partly a machine for sport and pleasure, partly an object that met the requirements of representing status (Fig. 2.2)."

Page 34, line 8: "Form of Representation (Fig. 2.5)" has been changed to "Form of Representation"

Page 34, line 12: "The glamor of a designer automobile body provided another medium to express the need for distinction of the monied aristocracy and of aristocrats by birth." has been changed to "The glamor of a designer automobile body provided another medium to express the need for distinction of the monied aristocracy and of aristocrats by birth (Fig. 2.5)."

Pages 50, $51 \& 52$, Table 3.1: The "period (.)" has been included at the end of each cell entries.

Page 104, line 1: "Users' Wishes and Conceptions of Mobility Are Decisive (Fig. 5.4)" has been changed to "Users' Wishes and Conceptions of Mobility Are Decisive"

Page 104, line 6: "The electric car is then no longer perceived solely as a vehicle that deviates undesirably from the combustion engine car, but also as something special." has been changed to "The electric car is then no longer perceived solely as a vehicle that deviates undesirably from the combustion engine car, but also as something special (Fig. 5.4)." 